\title{
The Levator Claviculae Muscle and Unilateral Third Head of the Sternocleidomastoid Muscle: Case Report
}

\author{
Músculo Elevador de la Clavícula y Tercera Cabeza Unilateral \\ del Músculo Esternocleidomastoídeo: Reporte de Caso
}

\author{
"Zeliha Fazliogullari; **Aynur Emine Cicekcibasi; **Nadire Unver Dogan; \\ "** Mehmet Tugrul Yilmaz; **Mustafa Buyukmumcu \& **Taner Ziylan
}

FAZLIOGULLARI, Z.; CICEKCIBASI, A, E.; UNVER DOGAN, N.; YILMAZ, M. T.; BUYUKMUMCU, M. \& ZIYLAN, T. The levator claviculae muscle and unilateral third head of the sternocleidomasto1d muscle: case report. Int. J. Morphol., 28(3):929932, 2010.

SUMMARY: A rare case of unilateral third head of sternocleidomastoid and an extra muscle - levator claviculae were determined unilaterally in a 70-year-old male cadaver during the routine dissections. In the left neck side, it was observed that the sternocleidomastoid muscle also had a third part in addition to known sternal and clavicular heads and levator claviculae muscle which arose from the posterior tubercle of the transverse process of the 3rd cervical vertebra and attached to the posterior margin of the clavicle. An awareness of this variations may be important because of its close relationship with neurovascular structures during neck operations.

KEY WORDS: Levator claviculae muscle, Sternocleidomastoid muscle; Neck; Anatomic variation.

\section{INTRODUCTION}

The sternocleidomastoid muscle takes place in the neck region as a surface marker and divides side of the neck into the anterior and lateral cervical regions (anterior and lateral triangles of the neck). The muscle has two heads as sternal part and clavicular part. While the sternal part holds to sternal manubrium through its round tendon, clavicular part holds to the upper side of clavicle horizontally. These parts go on obliquely upwards and end up at mastoid process and superior nuchal linea (Moore \& Dalley, 2006).

The levator claviculae muscle (cleidocervical muscle) is an extra muscle taking place in posterior cervical triangle (Tomo et al., 1994; Leon et al., 1995; Koshy et al., 2005). The incidence in the population was declared as 2-3\% (Wood, 1870). Although this muscle was initially reported by Kelch in 1813, its origo, insertio and length were described by Gruber (1876). The various definitions about holding places on transverse process of cervical vertebras and clavicle of the muscle various definitions about holding places are available (Tomo et al.; Leon et al.; Rosenheimer et al., 2000; Koshy et al.).

It is important to know anatomy and variations of these muscles during various operations in the neck region.

\section{CASE REPORT}

In the 70-year-old male cadaver, the variations of muscles connecting to clavicle were unilaterally determined in the left neck side. The third part of the sternocleidomastoid muscle was detected on clavicle in addition to sternal part and clavicular part (Fig. 1). When we went $6.9 \mathrm{~mm}$ towards lateral after sternal part originating from the anterior surface of sternal manubrium of sternocleidomastoid muscle and its clavicular part (12.3 $\mathrm{mm}$ wide) originating from medial of clavicle, its third part (12.6 mm wide) was found. It was observed that an extra muscle ( $16.5 \mathrm{~mm}$ wide) also attached to clavicle except from additional clavicular part of sternocleidomastoid muscle. Although this muscle was firstly evaluated as anterior scalen muscle, it was detected being levator claviculae muscle with further dissections and literature.

It was observed that the levator claviculae originated from the posterior tubercle of the $3^{\text {rd }}$ cervical vertebra and from a common tendon with levator scapulae muscle (Fig. 2). It was seen that it lied forward - downwards within the spesific fascial sheath separated from cervical fascia (profunda) and ended in the $1 / 2$ middle part of the above side of

\footnotetext{
* Selcuk University, Selcuklu Medical Faculty, Department of Anatomy, Konya, Turkey.

** Selcuk University, Meram Medical Faculty, Department of Anatomy, Konya, Turkey.
} 


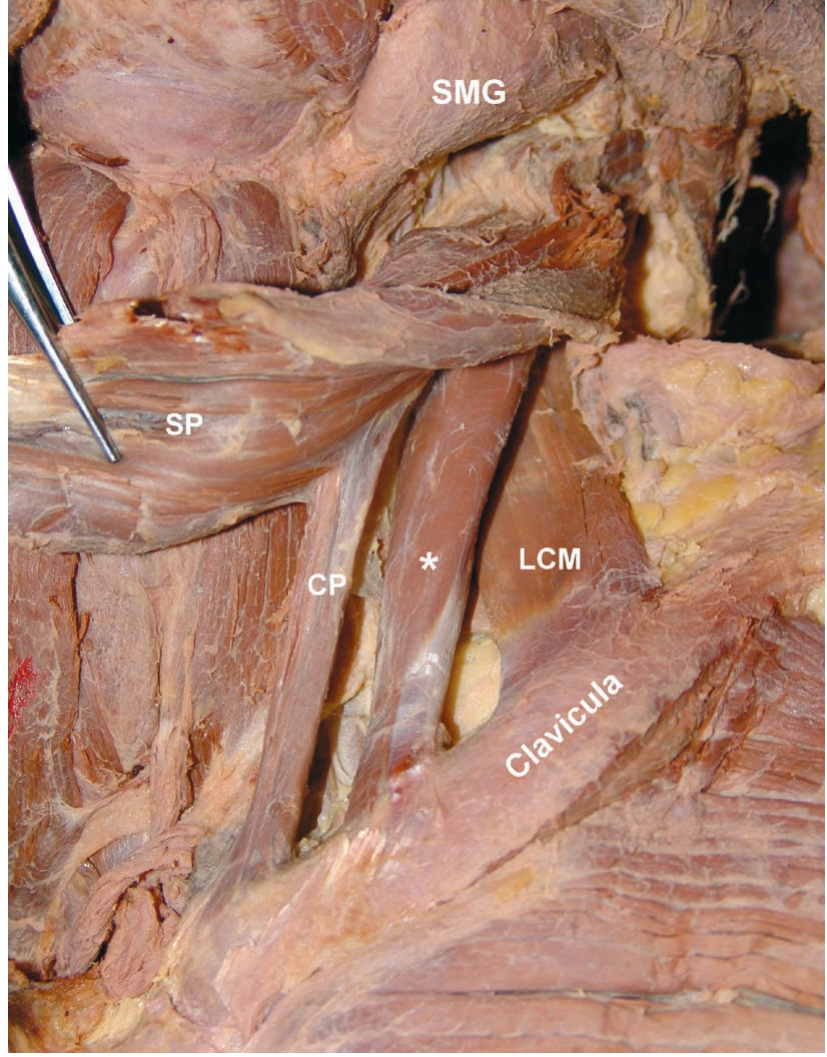

Fig. 1. The additional part of sternocleidomastoid muscle $(*)$ and the levator claviculae muscle (LCM) in the left cervical region. SMG. Submandibular gland; SP. Sternal part; CP. Clavicular part.

clavicle (clavicle length $13 \mathrm{~cm}$ ) and the attached point had tubercular structure. The length and width of the muscle was determined as $90.95 \mathrm{~mm}$ and $16.75 \mathrm{~mm}$ (the widest place), respectively. In this case, the scalenus anterior, the scalenus medius and the scalenus posterior muscles attached to the first costa, and neurovascular structures situated between these muscles were in their normal anatomic positions.

\section{DISCUSSION}

The known variations of the sternocleidomastoid are generally related with its origin. The muscle can especially join with trapezius muscle relating to insertion place. It was considered that both muscles were developed from the same miyotome as the reason of this fusion (Bergman et al., 1988). Unilateral (Cherian \& Nayak, 2008; Coskun et al., 2002) and bilateral variations were reported the additional parts concerning the origin of the muscle (Ramesh et al., 2007). In these studies, the additional clavicular part was detected

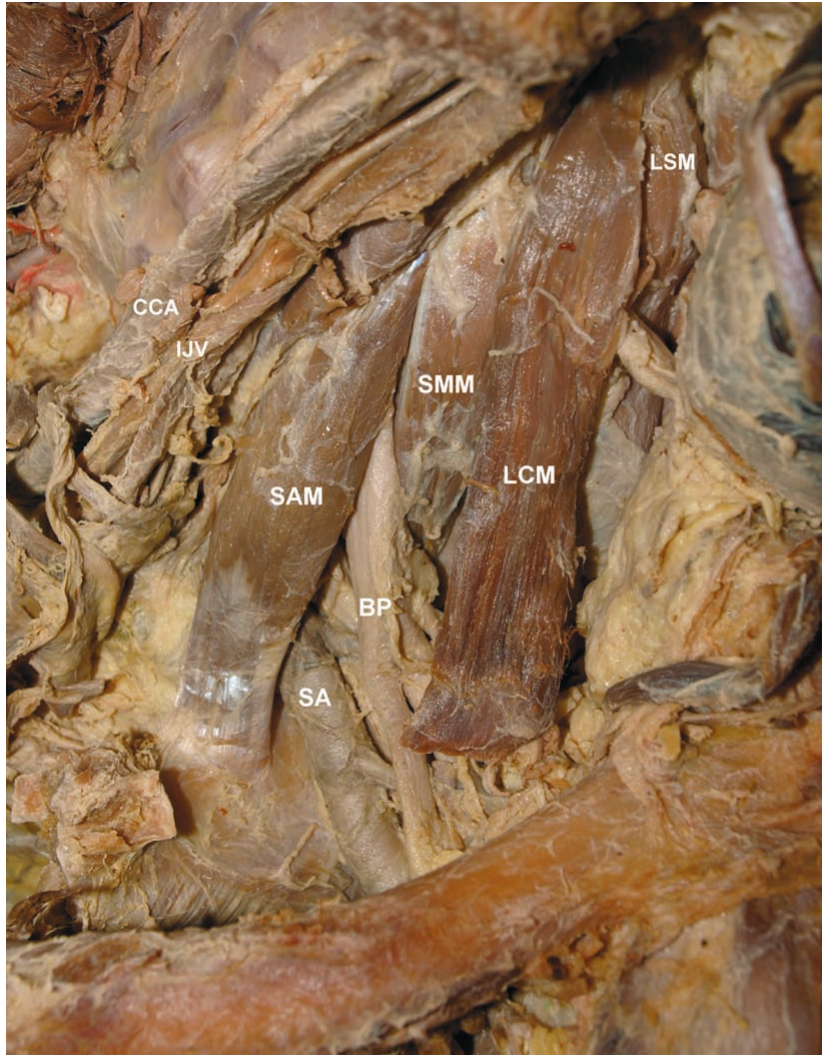

Fig. 2. Lateral view of the left side of the neck after removal of the sternocleidomastoid muscle to show the relations of the levator claviculae muscle (LCM). CCA. Common carotid artery; IJV. Internal jugular vein; SAM. Scalenus anterior muscle; SA. Subclavian artery; BP. Brachial plexus: SMM. Scalenus medius muscle; LSM- Levator scapulae muscle.

as observed in our case.

The sternocleidomastoid muscle has five different parts which were declared by various researchers (Bergman et al.; Sanli et al., 2006) according to the attached places. These were reported as superficial sterno-mastoid, sternooccipital, cleido-occipital, deep sterno-mastoid and cleidomastoid. Sanli et al. reported the existence of cleido-occipital muscle as $33 \%$. In our case, it was also determined the cleido-occipital part.

The knowledge of the variations of sternocleidomastoid muscle is especially important for plastic surgery because this muscle has different use areas (the repair of the mandibula defects, the use as flap in reconstruction of the mouth skeleton and the create of the suture line in the protection of common carotid and surrounding arteries) (Conley \& Gullane, 1980). The selection chance can provide for finding the most appropriate part in the flap use that the muscle has additional parts (Ramesh et al.). 
The levator claviculae muscle is usually seen in human-like mammalians and in most of other mammalian groups. However, it is not available in human (Parsons, 1898). There are various hypotheses which explain the embryological origin of this muscle. It was reported that the levator claviculae muscle originated from the sternocleidomastoid muscle (Wood), the trapezius muscle (Parsons), the scalenus anterior muscle (Gruber, 1876) or the longus colli muscle (Tomo et al.). It can be considered that this muscle originated from primordiums of ventrolateral neck muscles (the scalenus, anterior vertebral, infrahyoid muscles) when taken into account that it started from cervical vertebras while the primordiums of the sternocleidomastoid and the trapezius muscles started from the occipital region (Leon et al.). Gruber (1876) declared that it originated from the scalenus anterior muscle. In this study this muscle was firstly evaluated as the scalenus anterior muscle. However, it was detected being levator claviculae muscle with further dissections and literature.

Tomo et al. reported that this muscle originated from the longus colli muscle and the omohyoideus muscle, the superficial cervical artery, the phrenic nerve and the inferior ramus of the cervical ansa placed between the scalenus anterior muscle and the levator claviculae muscle. They stated that the muscle helped thorax expansion during inspiration when the clavicle was kept constant. In addition, they stated that it developed in the subsequent steps from the scalenus anterior muscle because of the scalenus anterior muscle and the levator claviculae muscle helped to respiration.

The different places of origin and insertion of the levator claviculae muscle were described. While the transverse process of the axis, (Leon et al.), the transverse process of the the sixth cervical vertebra (Rosenheimer et $a l$.) or the anterior tubercle (Tomo et al.), the transverse process of the atlas and axis (Koshy et al.) were shown as the origin place, the posterior margin of clavicle (Tomo et al.; Rosenheimer et al.), the 1/3 middle (Leon et al.) or 1/3 lateral part (Koshy et al.) of posterior surface were shown as the insertio place. In this case, it was determined that the levator claviculae muscle started from the posterior tubercle of the third cervical vertebra and ended in the $1 / 3$ middle region of posterior margin of clavicle. While it started from the common tendon with the levator scapulae muscle in the origin point, similarly Leon et al. also declared that it started from transverse process of the axis forming a common fascicle with the levator scapulae muscle.

The levator claviculae muscle can be confused with soft tissue masses such as lymphadenopati and thromboses vein during physical examination. However it can be detected easily with modern screening techniques because of apparent muscular course (Rubinstein et al., 1999; Ruiz Santiago et al., 2001; Aydog et al., 2006). It is necessary to know this variation was compared by radiologists. Rubinstein et al., determined it in $2 \%$ ratio on $300 \mathrm{CT}$ as reported by Wood. They reported that it was usually seen as unilateral left side as in our case.

The confused situations can be observed during clinical applications and radiological screening in the case that the third part of the sternocleidomastoid muscle and the presence of the levator claviculae muscle can be detected.

FAZLIOGULLARI, Z.; CICEKCIBASI, A, E.; UNVER DOGAN, N.; YILMAZ, M. T.; BUYUKMUMCU, M. \& ZIYLAN, T. Músculo elevador de la clavícula y tercera cabeza unilateral del músculo esternocleidomastoídeo: reporte de un caso. Int. J. Morphol., 28(3):929-932, 2010.

RESUMEN: Durante una disección de rutina, se observó en un cadáver de sexo masculino de 70 años de edad, la presencia de una tercera cabeza unilateral del músculo esternocleidomastoideo y de un músculo elevador clavicular accesorio. En el lado izquierdo del cuello, se observó que el músculo esternocleidomastoideo poseía una tercera cabeza, además de las cabezas esternal y clavicular . El músculo elevador de la clavícula, tenía su origen en el tubérculo posterior del proceso transverso de la tercera vértebra cervical y se insertaba en el margen posterior de la clavícula. El conocimiento de estas variaciones pueden ser importantes debido a su estrecha relación con las estructuras neurovasculares del cuello durante las operaciones.

PALABRAS CLAVE: Músculo elevator clavicular, Músculo esternocleidomastoideo; Cuello; Variación anatomica.

\section{REFERENCES}

Aydog, S.T.; Ozcakar, L.; Demiryurek, D.; Bayramoglu, A. \& Yorubulut, M. Levator claviculae muscle in a male gymnast: A rare variation. Neuroanatomy, $10^{\text {th }}$ National Congress of Anatomy Bodrum, Turkey, September 5:6-10, 2006.
Bergman, R. A.; Thomson, S. A.; Afifi, A. K. \& Saadeh, F. A. Compendium of anatomic variation. In: muscles. Urban and Schwarzenberg, Baltimore, 1988. pp. 32-3. 
Cherian, S. B. \& Nayak, S. A rare case of unilateral third head of sternocleidomastoid muscle. Int. J. Morphol., 26(1):99-101, 2008.

Conley, J. \& Gullane, P. J. The sternocleidomastoid muscle flap. Head Neck Surg., 2(4):308-11, 1980.

Coskun, N.; Yildirim, F. B. \& Ozkan, O. Multiple muscular variations in the neck region--case study. Folia Morphol., 61(4):317-9, 2002.

Gruber, W. Ein Musculus cleido-cervicalis s. tracheloclavicularis imus. Archiv fur anatomische, physiologische und wissenschaftliche Medizin, 757-8, 1876.

Koshy, S.; Rabi, S. \& Indrasingh, I. Supernumerary cleidocervicalis (levator claviculae) muscle: case report of its rare incidence with clinical and embryological significance. Eur. J. Anat., 9 (2):103-6, 2005.

Leon, X.; Maranillo, E.; Quer, M. \& Sañudo, J. R. Case report: cleidocervical or levator claviculae muscle: a new embryological explanation as to its origin. J. Anat., 187:503-4, 1995.

Moore, K. L \& Dalley, A. F. Clinically Oriented Anatomy. 5th Ed. Baltimore, Lippincott, Williams \& Wilkins, 2006. p. 1053 .

Parsons, F. G. The muscles of mammals, with special relation to human myology. J. Anat. Physiol., 32:721-52, 1898.

Ramesh, R. T.; Vishnumaya, G.; Prakashchandra, S. K. \& Suresh, R. Variation in the origin of sternocleidomastoid muscle. A case report. Int. J. Morphol., 25(3):621-3, 2007.

Rosenheimer, J. L.; Loewy, J. \& Lozanoff, S. Levator claviculae muscle discovered during physical examination for cervical lymphadenopathy. Clin. Anat., 13:298-301, 2000.

Rubinstein, D.; Escott, E. J. \& Hendbrick, L. L. The prevalence and CT appearance of the levator claviculae muscle: a normal variant not to be mistaken for an abnormality. Am. J. Neuroradiol., 20:583-6, 1999.

Ruiz Santiago, F. R.; López Milena, G.; Chamorro Santos, C. \& Tristán Fernandez, J. M. Levator claviculae muscle presenting as a hard clavicular mass: imaging study. Eur Radiol., 11(12):2561-3, 2001.
Sanli, E.C.; Kurtoglu, Z.; Ozturk, A.H. \& Aktekin, M. Detailed anatomy of five parts of the sternocleidomastoid muscle. Neuroanatomy. 10th National Congress of Anatomy Bodrum, Turkey, September 5:6-10, 2006.

Tomo, S.; Toh, H.; Hirakawa, T.; Tomo, I. \& Kobayashi, S. Case report: the cleidocervical muscle with speculation as to its origin. J. Anat., 184:165-9, 1994.

Wood, J. On a group of varieties of the muscles of the human neck, shoulder, and chest with their transitional forms and homologies in the mammalia. Philos. Trans. R. Soc. Lond., 160:83-116, 1870.

\section{Correspondence to:}

Zeliha Fazlıogullari

Selcuk University

Selcuklu Medical Faculty,

Department of Anatomy, 42075,

Konya

TURKEY

Phone number: +9003322415000- 40047

Fax number: +9003322412184

Email: z_topal@yahoo.com

Received: 28-12-2009

Accepted: 24-03-2010 